\title{
Putting the efficacy of psychiatric and general medicine medication into perspective: review of meta-analyses
}

Stefan Leucht, Sandra Hierl, Werner Kissling, Markus Dold and John M. Davis

\section{Background}

The efficacy of psychopharmacological treatments has been called into question. Psychiatrists are unfamiliar with the effectiveness of common medical drugs.

\section{Aims}

To put the efficacy of psychiatric drugs into the perspective of that of major medical drugs.

\section{Method}

We searched Medline and the Cochrane Library for systematic reviews on the efficacy of drugs compared with placebo for common medical and psychiatric disorders, and systematically presented the effect sizes for primary efficacy outcomes.

\section{Results}

We included 94 meta-analyses (48 drugs in 20 medical diseases, 16 drugs in 8 psychiatric disorders). There were some general medical drugs with clearly higher effect sizes than the psychotropic agents, but the psychiatric drugs were not generally less efficacious than other drugs.

\section{Conclusions}

Any comparison of different outcomes in different diseases can only serve the purpose of a qualitative perspective. The increment of improvement by drug over placebo must be viewed in the context of the disease's seriousness, suffering induced, natural course, duration, outcomes, adverse events and societal values.

\section{Declaration of interest}

In the past 3 years S.L. has received fees for consulting and/ or lectures from the following companies: Bristol-Myers Squibb, Actelion, Sanofi-Aventis, Eli Lilly, Essex Pharma, AstraZeneca, MedAvante, Alkermes, Janssen/Johnson \& Johnson, Lundbeck Institute and Pfizer, and grant support from Eli Lilly. W.K. has received fees for consulting and/or lectures from Janssen-Cilag, Sanofi-Aventis, Johnson \& Johnson, Pfizer, Bristol-Myers Squibb, AstraZeneca, Lundbeck, Novartis and Eli Lilly. All authors work in psychiatry.
There is a deep mistrust of psychiatry fostered by reports suggesting that psychotropic drug efficacy is very small. Kirsch et al concluded that antidepressants should only be used in severely ill patients; ${ }^{1}$ the efficacy of cholinesterase inhibitors in Alzheimer's disease and of lithium prophylaxis in bipolar disorder has been questioned; ; ${ }^{2,3}$ and we found a smaller antipsychotic drug-placebo difference in schizophrenia than we intuitively expected. ${ }^{4}$ These reviews inspired an article in The New Yorker summarising them, ${ }^{5}$ and fuelled a vocal antipsychiatry movement. ${ }^{6,7}$ Psychiatrists, patients, caregivers and the press are unsettled by these findings and some may think that psychiatric medication is not worth the bother. But is this small efficacy really true, and what about other medical interventions? As medicine is becoming highly specialised, few psychiatrists are familiar with the evidence of general medicine and psychiatric drugs. In this context we reviewed the efficacy of psychiatric pharmacotherapy in the perspective of standard medical drugs, making this paper the first attempt to provide a panoramic overview of major drugs. It is not possible to compare qualitatively different outcomes in qualitatively different diseases, but one can compare the percentages of patients helped with a drug or placebo, keeping in mind the differences in outcome for the mere purpose of perspective. We hasten to add a warning not to be overly concrete and to interpret this review as a qualitative perspective and not as a comparison. Therefore we discuss major factors that need to be taken into account in the interpretation of clinical trials and systematic reviews.

\section{Method}

\section{Identification of diseases of interest and search strategy}

We reviewed textbooks, ${ }^{8,9}$ identified common diseases by consensus (S.L., S.H. and J.M.D.) based on frequency, importance and available treatment, and consulted national and international guidelines to identify primary treatments. We hand-searched the Cochrane Library, and searched Medline combining MeSH terms for the medical and psychiatric disorders with the MeSH term for meta-analysis (no time or language limit, last search May 2009) and references of included reports for systematic reviews of randomised controlled trials that applied meta-analysis and compared monotherapy of these treatments with placebo.

We first excluded meta-analyses of studies of subgroups (e.g. elderly people) and chose reviews of classes of drugs rather than single drugs (e.g. any antipsychotic, rather than only haloperidol) if available, based on the assumption that the original reviewers had made an appropriate decision to pool the drugs. We then chose the most recent reviews, because even if methodologically better an older review would have certainly been out of date. This was a conservative decision, because old meta-analyses in psychiatry usually had higher effect sizes (see Discussion and online Table DS1). The rare exceptions were slightly older metaanalyses that reported the indices necessary for our analysis more completely. These usually were Cochrane reviews which were 
preferred in case of doubt, because they use similar methodology and always fully report the data. To corroborate these decisions we always compared different reviews for consistency of results and contacted authors in the rare case that the results were discrepant. (These additional reviews are quoted in the footnotes of the tables in the online data supplement.) The quality of the included systematic reviews was evaluated with the AMSTAR score (range of possible values $0-11) .{ }^{10}$ Only primary efficacy outcomes in the areas of interest according to the treatment guidelines were extracted.

\section{Statistical analysis}

For continuous outcomes we extracted effect sizes and their 95\% confidence intervals, presented both as differences in original units (mean difference) and as standardised mean differences (SMD). Mean differences were calculated according to the general formula (mean group A) - (mean group B), e.g. $75 \mathrm{~kg}$ in the drug group minus $70 \mathrm{~kg}$ in the placebo group gives a mean difference in body weight of $5 \mathrm{~kg}$. Standardised mean differences (SMDs) provide a difference in standard deviation units (mean group A-mean group B) / standard deviation, e.g. $(75-70) / 10=0.50$, using the values from the previous example.

For dichotomous outcomes we presented the percentage of participants improved in the drug and placebo groups, the absolute risk/response difference (ARD; \% responder drug-\% responder placebo); the relative risk reduction (RRR; $1-(\%$ risk drug/\% risk placebo) or relative response (RR) ratio (\% responder drug / \% responder placebo); and the number needed to treat (NNT), with their $95 \%$ confidence intervals. We also presented the $P$ value, the number of studies and participants included and the average study duration (see online Table DS2 for a detailed description of these parameters).

Where our five standard parameters (mean difference, SMD, ARD, RRR, RR, NNT) were not reported in the studies, we transformed the existing data, or re-calculated meta-analyses by entering single study results using Review Manager version 5.0 or Comprehensive Meta-analysis version 2 for Windows. ${ }^{11,12}$ S.H. ran the searches, S.H. and S.L. selected the reports. S.H. extracted the data, S.L. independently verified them, disagreements were resolved by J.M.D. and W.K., and M.D. rated the AMSTAR score.

\section{Results}

The Medline searches yielded 6175 abstracts and we handsearched 1830 titles of Cochrane reviews - see online Figs DS124 for Preferred Reporting Items for Systematic Reviews and Meta-analyses (PRISMA) diagrams of the selection process. ${ }^{13}$ We included 94 meta-analyses of 48 drugs in 20 medical diseases (median AMSTAR score 9.0, 95\% CI 8.2-9.2) and 33 metaanalyses of 16 drugs in 8 psychiatric disorders (median AMSTAR score 8.0, 95\% CI 6.9-8.9). In the text we systematically present the raw numbers (for dichotomous outcomes the percentage responders in the placebo and drug groups; for continuous outcomes the average mean difference) and the average effect size (ARD and RRR/RR for dichotomous outcomes, SMD for continuous outcomes). Tables 1 and 2 present only some examples. Online Tables DS3 and DS4 present a comprehensive list including number of studies/participants, numbers needed to treat, $P$ values and confidence intervals for each outcome and each intervention. A positive sign means that a drug either increased a positive outcome (e.g. response) or reduced a negative outcome (e.g. relapse). All the effect sizes in online Tables DS3 and DS4 are presented in Fig. 1 to give the overall gestalt. For this purpose, effect sizes for dichotomous outcomes (ARD, RR/RRR) were converted to SMDs in Comprehensive Meta-analysis $2 .^{12,14}$ This figure corresponds to online Fig. DS25 which indicates which dot relates to which study or outcome. Figures DS26 and DS28 present the same gestalt for relative and absolute risk/responder differences.

\section{Medical disorders}

In Tables 1 and DS3 the data are presented in an abbreviated 'participants - intervention - comparator - outcome' (PICO) format (the comparator is always placebo or no treatment).

Hypertension: antihypertensives for reduction of blood pressure, prevention of cardiovascular events and mortality

Several drug classes yielded similar results (Table DS3). Combining all agents, blood pressure was reduced by $9.4 \mathrm{mmHg}$ systolic and $5.5 \mathrm{mmHg}$ diastolic in the short term (SMDs 0.54 and 0.56 respectively). ${ }^{15}$ In the long term all drug classes significantly reduced cardiovascular events, e.g. angiotensin-converting enzyme (ACE) inhibitors reduced such events from $18 \%$ to $14 \%$ (ARD $4 \%$, RRR 22\%). ${ }^{16}$ A significant reduction of mortality has not been shown for all of them (Table DS3).

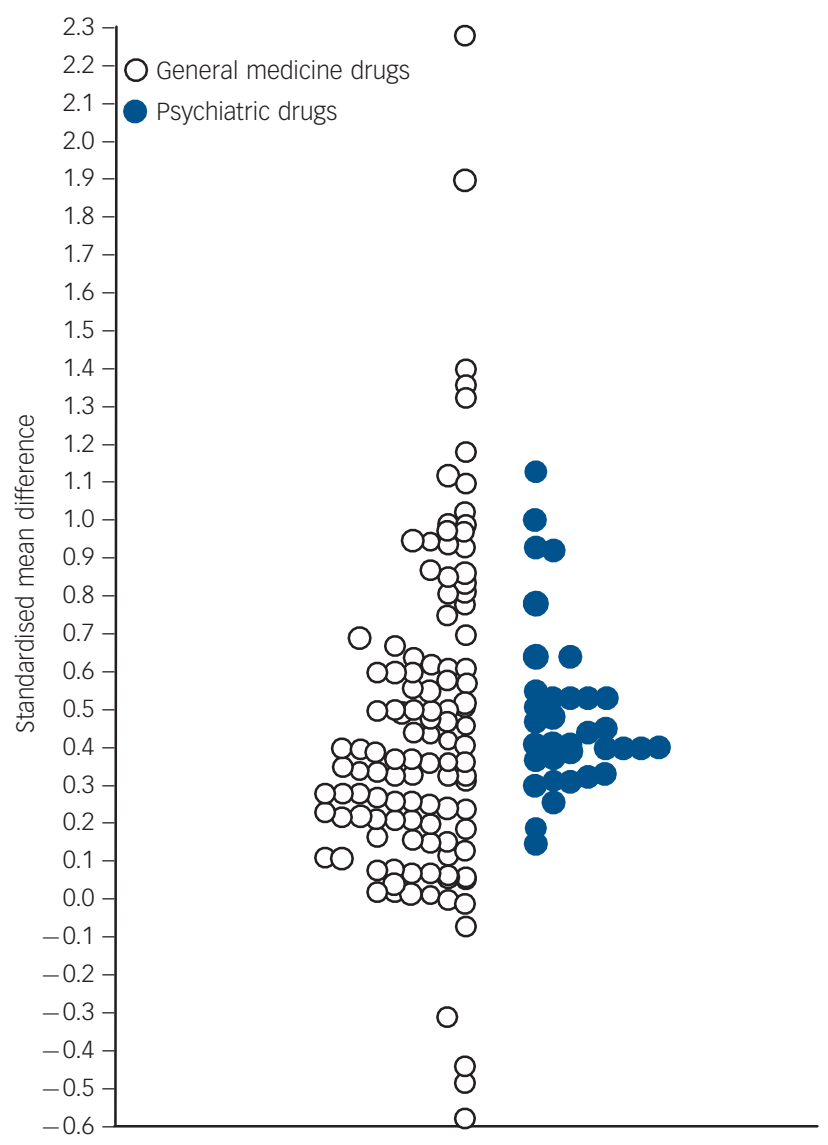

Fig. 1 Summary of effect sizes.

All effect sizes in online Tables DS3 and DS4 are presented except for duplicates (e.g. effect size on dichotomous response and continuous reduction of severity in schizophrenia). Online Fig. DS25 identifies which dot corresponds to which result, and Figs DS26-29 present the results of dichotomous outcomes as relative and absolute risk/responder differences. Data on older meta-analyses from Table DS1 are not included. Effect sizes of dichotomous outcomes were converted to standardised mean differences expressed as Hedges' $g$. Effect sizes of general medicine medication are presented on the left-hand side (median 0.37, mean $0.45,95 \%$ $\mathrm{Cl} 0.37-0.53$ ) and psychiatric drugs on the right-hand side (median 0.41, mean 0.49, $95 \% \mathrm{Cl} 0.41-0.57)$. 


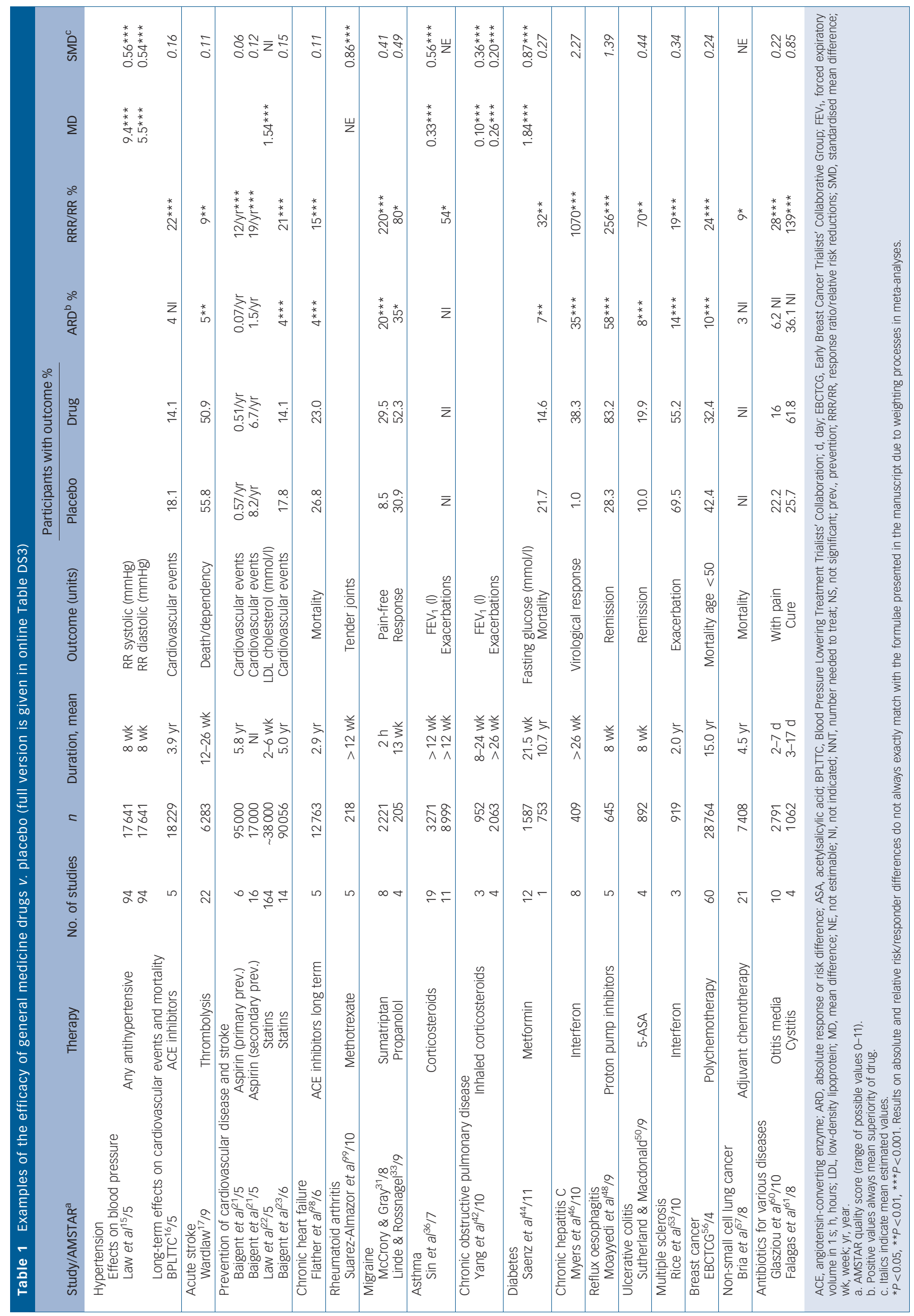


Acute ischaemic stroke: thrombolysis, aspirin and heparin for prevention of death or dependency

Thrombolysis reduced death or dependency from $56 \%$ to $51 \%$ (ARD 5\%, RRR 9\%), ${ }^{17}$ but when administered after $4.5 \mathrm{~h}$ mortality is increased by haemorrhages. ${ }^{18}$ Aspirin reduced death or dependency from $46 \%$ to $45 \%,{ }^{19}$ whereas heparin was ineffective. ${ }^{20}$

Cardiovascular disease: aspirin for primary and secondary prevention of cardiovascular events and mortality

In secondary prevention, low-dose aspirin reduced serious cardiovascular events per year from $8.2 \%$ to $6.7 \%$ (ARD 1.5\%, RRR $19 \%$ ) and vascular mortality per year from $4.1 \%$ to $3.7 \%$ (ARD $0.29 \%$, RRR 9\%, $P=0.05$ ). ${ }^{21}$ In primary prevention, aspirin reduced the number of cardiovascular events per year from $0.57 \%$ to $0.51 \%$, but there was no effect on mortality because the reduction of occlusive events was balanced by an increase in major bleeds (mortality per year: placebo $0.19 \%$, drug $0.19 \%$ ). ${ }^{21}$

Hypercholesterolaemia: statins for reduction of cholesterol levels and prevention of cardiovascular disease and mortality

In the short term, statins reduced low-density lipoprotein (LDL) cholesterol by $1.54 \mathrm{mmol} / 1$ or $31 \% .^{22}$ In the long term, cardiovascular events were reduced from $18 \%$ to $14 \%$ (primary and secondary prevention combined, ARD 4\%, RRR 21\%) and 5-year mortality from $9.7 \%$ to $8.5 \% .^{23}$

\section{Chronic heart failure: various drugs for reduction of mortality}

Angiotensin-converting enzyme inhibitors, angiotensin receptor blockers, beta-blockers and diuretics respectively reduced mortality rates from $27 \%$ to $23 \%$ (ARD $4 \%$, RRR $15 \%$ ), from $18 \%$ to $11 \%$, from $13 \%$ to $8 \%$ and from $12 \%$ to $3 \%{ }^{24-27}$ Digitalis significantly reduced hospital admission (from 33\% to 25\%) but not mortality. ${ }^{28}$

\section{Rheumatoid arthritis: antirheumatic drugs for the reduction} of tender joints

Various immunosuppressants, corticosteroids and other agents reduced the number of tender joints with reasonably good SMDs between 0.33 and 1.33 (raw values for mean differences were not presented; Table DS3). ${ }^{29,30}$

Acute migraine: effects of sumatriptan and aspirin

on the number of patients pain-free after $2 \mathrm{~h}$

Sumatriptan increased the percentage of patients pain-free after $2 \mathrm{~h}$ from $9 \%$ to $30 \%$ (ARD 20\%, RR 220\%) ) $^{31}$ and intravenous aspirin increased it from $15 \%$ to $27 \%$. $^{32}$

Prophylaxis of migraine: effects of propanolol and anticonvulsants on responder rates and on the number of migraine attacks

Fifty-two per cent responded to propanolol prophylaxis and 31\% to placebo (ARD 35\%, RR 80\%). ${ }^{33}$ Patients had approximately one migraine attack less (SMD 0.47). ${ }^{33}$ The results of anticonvulsants were similar. ${ }^{34}$

Chronic asthma: effects of inhaled corticosteroids and beta-2-agonists on forced expiratory volume and on asthma exacerbations

The first-line drugs for chronic, severe asthma are inhaled corticosteroids and beta-2-agonists (short-acting as needed, long-acting in patients with refractory disease). ${ }^{35}$ Inhaled corticosteroids increased forced expiratory volume in $1 \mathrm{~s}\left(\mathrm{FEV}_{1}\right)$ by
$330 \mathrm{ml}$ (SMD 0.56). ${ }^{36}$ The addition of long-acting beta-2-agonists improved $\mathrm{FEV}_{1}$ by $190 \mathrm{ml}$ (SMD 0.35), ${ }^{37}$ but the reduction of asthma exacerbations found by some meta-analyses is controversial, ${ }^{36,38}$ because another meta-analysis found more severe exacerbations. $^{39}$

Chronic obstructive pulmonary disease: effects of various agents on $\mathrm{FEV}_{1}$ and on disease exacerbations

Guidelines recommend anticholinergics, beta-2-agonists and inhaled corticosteroids. ${ }^{40}$ The anticholinergic tiotropium improved $\mathrm{FEV}_{1}$ by $200 \mathrm{ml}$ (SMD 0.99). ${ }^{41}$ It reduced exacerbations from $31 \%$ to $23 \%$ (ARD 5\%, RRR 17\%). ${ }^{41}$ Inhaled corticosteroids improved $\mathrm{FEV}_{1}$ by $100 \mathrm{ml}$ (SMD 0.36) and the number of exacerbations per patient and year by 0.26 (SMD 0.20). ${ }^{42}$ The data on long-acting beta-2-agonists are equivocal. They reduced exacerbations (e.g. Salpeter et al), ${ }^{43}$ but one systematic review found them to increase respiratory deaths. ${ }^{43}$

Type 2 diabetes: various antidiabetics for reduction of $\mathrm{HbA}_{1 \mathrm{c}}$ and mortality

Metformin reduced $\mathrm{HbA}_{1 \mathrm{c}}$ by $1 \%$ (SMD 0.97 ) and $\alpha$-glucosidase inhibitors reduced it by $0.8 \%$ (SMD 0.64). ${ }^{44,45}$ In the long term, metformin reduced the death rate from $22 \%$ to $15 \%$ (ARD $7 \%$, RRR 32\%), ${ }^{44}$ but $\alpha$-glucosidase inhibitors have not been shown to change the death rate. ${ }^{45}$

Hepatitis C: effects of interferon and ribavirin on virological response/morbidity and mortality

Interferon increased the number of participants with no detectable virus at treatment end (virological response) from $1 \%$ to $38 \%$ (ARD 35\%, RR 1070\%). ${ }^{46}$ Ribavirin was only efficacious in combination with interferon. ${ }^{47}$

Reflux oesophagitis: proton pump inhibitors for clinical remission and relapse prevention

Proton pump inhibitors are highly effective in acute treatment (response: placebo 28\%, drug 83\%, ARD 58\%, RR 256\%), ${ }^{48}$ and also in maintenance treatment (relapse: placebo $75 \%$, drug $36 \%) .{ }^{49}$

Ulcerative colitis: 5-aminosalicylic acid for clinical remission and maintenance of remission

Five-aminosalicylic acid (5-ASA) increased remission from $10 \%$ with placebo to $20 \%$ (ARD $8 \%$, RR 70\%), ${ }^{50}$ and maintenance of remission from $37 \%$ to $53 \%$ (ARD $18 \%$, RR $50 \%$ ). ${ }^{51}$

Multiple sclerosis: corticosteroids for treatment of acute episodes and interferon for prevention of exacerbations

Acute treatment with corticosteroids increased the proportion of responders from $28 \%$ with placebo to $68 \%$ (ARD $41 \%$, RR $140 \%){ }^{52}$ In the first 2 years, prevention with interferon beta reduced exacerbations from $70 \%$ to $55 \%$ (ARD 14\%, RRR 19\%). ${ }^{53}$

\section{Parkinson's disease: effects of levodopa on disease symptoms}

There was no systematic review of the standard treatments levodopa or dopamine agonists with data compared with placebo. We parenthetically note that the National Institute for Health and Clinical Excellence (NICE) guideline based its recommendation on a pivotal 42 -week trial in which levodopa produced 7 points more improvement in the Unified Parkinson's Disease Rating 
Scale total score than placebo (SMD 0.93), ${ }^{54}$ but also a $7 \%$ stronger decline of striatal dopamine transporter density (SMD -0.44 ), suggesting a possible acceleration of nigrostriatal dopamine nerve terminal loss. ${ }^{55}$

\section{Breast and lung cancer: polychemotherapy for reduction of mortality}

Breast cancer is the most frequent neoplasm in women and lung cancer is the leading cause of cancer death. Polychemotherapy reduced the 15 -year breast cancer mortality in younger women ( $<50$ years) from $42 \%$ to $32 \%$ (ARD $10 \%$, RRR 24\%) but in older women only from $50 \%$ to $47 \%{ }^{56}$ Tamoxifen added to polychemotherapy reduced the 15 -year mortality in oestrogen receptor-positive patients from $35 \%$ to $26 \%{ }^{56}$ In the study by Bria et al, adjuvant chemotherapy led to a small reduction of 5-year lung-cancer mortality (ARD 3\%, RRR 9\%), ${ }^{57}$ confirming a landmark previous meta-analysis. ${ }^{58}$

Infectious diseases: antibiotics for rhinosinusitis, otitis media, uncomplicated cystitis and prophylaxis of wound infection after surgery

The effects of antibiotics depend on the infection. We did not find meta-analyses on severe infections such as pneumonia or on antivirals (monotherapy v. placebo) for HIV. A meta-analysis concluded against their general use in rhinosinusitis owing to small effect size (response: placebo 57\%, drug 64\%, ARD 7\%, RRR $13 \%) .{ }^{59}$ The use of antibiotics in otitis media is debated, as within 2-7 days $78 \%$ of patients recovered spontaneously compared with $84 \%$ taking antibiotics (ARD 6\%, RR 28\%). ${ }^{60}$ In contrast, the efficacy in uncomplicated cystitis (response: placebo $26 \%$, drug $62 \%$ ) and for the prophylaxis of wound infections after major operations (infections: placebo 39\%, antibiotics 10\%) was clear. $^{61,62}$

\section{Psychiatric disorders}

Full data are given in Table DS4; examples are summarised in Table 2.

\section{Schizophrenia: antipsychotics for reduction of overall symptoms and relapse prevention}

In acute treatment, second-generation antipsychotics increased the percentage responding from $24 \%$ with placebo to $41 \%$ (ARD 18\%, RR 70\%), and reduced the Brief Psychiatric Rating Scale/Positive and Negative Syndrome Scale total score by 9/10 points (SMD 0.51). ${ }^{4}$ Antipsychotic maintenance treatment reduced relapse rates from $57 \%$ to $22 \%$ within approximately 10 months (ARD 38\%, RRR 65\%). ${ }^{63}$

Bipolar disorder: mood stabilisers for acute mania, antidepressants for depression and mood stabilisers for relapse prevention

Various antimania agents increased the percentage responding from approximately $30 \%$ with placebo to approximately $50 \%$ within 3 weeks (response to lithium 52\% v. placebo 34\%, ARD $17 \%$, RR $50 \% ;{ }^{64}$ response to valproate $47 \%$ v. placebo $21 \%$, ARD $27 \%$, RR $150 \% ;{ }^{65}$ response to carbamazepine $51 \% v$. placebo $26 \%$, ARD $25 \%$, RRR $100 \%$; ${ }^{65}$ response to antipsychotics $50 \% v$. placebo $31 \%$, ARD $20 \%$, RR 60\%). ${ }^{66}$ In bipolar depression, antidepressants increased the response rate from $34 \%$ to $58 \%$ (ARD 34\%, RR 130\%). ${ }^{67}$ In maintenance treatment, lithium reduced relapse rates from $81 \%$ to $36 \%$ (ARD 53\%, RRR $51 \%),{ }^{68}$ or from $61 \%$ to $40 \%$ after excluding studies in which lithium was suddenly discontinued (ARD 24\%, RRR 35\%). ${ }^{69}$
Major depressive disorder: antidepressants for acute depression and relapse prevention

The absolute responder differences in recent meta-analyses of various selective serotonin reuptake inhibitors (SSRIs) (or tricyclic antidepressants used as an active comparator in SSRI $v$. placebo studies $^{70} v$. placebo in major depressive disorder were $10-15 \%$ (Table DS4). For example, paroxetine increased the percentage responding from $42 \%$ to $53 \%$ (ARD 10\%, RR 20\%) and reduced the Hamilton Rating Scale for Depression score by 3 points (SMD 0.32). ${ }^{71}$ These studies were currently primarily conducted in out-patients with less severe disorder (e.g. $90 \%$ of the sample were out-patients in the meta-analysis by Barbui et al). ${ }^{71}$

Maintenance treatment with any antidepressant reduced the relapse rate from $41 \%$ with placebo to $18 \%$ (ARD 23\%, RRR $58 \%),{ }^{72}$ consistent with another meta-analysis restricted to new antidepressants (placebo 48\% v. drug 26\%, ARD 22\%, RRR $44 \%){ }^{73}$

\section{Obsessive-compulsive disorder: effects of SSRIs on responder rates and overall symptoms}

Selective serotonin reuptake inhibitors increased the proportion of patients responding in the acute phase from 23\% to $43 \%$ (ARD $20 \%$, RRR $84 \%) .{ }^{74}$ These drugs reduced the mean Yale-Brown Obsessive Compulsive Scale score by 3.2 points (SMD 0.44). ${ }^{74}$

\section{Panic disorder: tricyclic antidepressants, SSRIS}

and benzodiazepines for anxiety symptoms

The mean SMDs (raw differences in rating scale scores or responder rates were not indicated) of tricyclic antidepressants, SSRIs and benzodiazepines in acute treatment were $0.40-0.41 .^{75}$

\section{Alzheimer's disease: cholinesterase inhibitors for prevention} of cognitive decline

Within 6 months, cholinesterase inhibitors increased the percentage of participants unchanged or improved from $17 \%$ to 24\% (ARD 7\%, RRR 43\%). ${ }^{76}$ The cognitive subscore of the Alzheimer's Disease Assessment Scale was better by 2 points (SMD 0.41). ${ }^{76}$

\section{Attention-deficit hyperactivity disorder: effects of various drugs on symptoms}

Methylphenidate (SMD 0.78), amphetamines (SMD 1.00) and atomoxetine (SMD 0.64) showed robust effect sizes in overall reduction of attention-deficit hyperactivity disorder symptoms (raw differences in rating scale scores or responder rates were not indicated). ${ }^{77-79}$

\section{Discussion}

Any comparison of treatments for different diseases can only be qualitative in nature and therefore Fig. 1 is no more than a way to place psychiatric drugs in the perspective of general medicine medication. Some general medical drugs have very high effect sizes, but those obtained by psychiatric drugs are in the same range as most general medical pharmacotherapeutics. This said, the increment of improvement by a drug must be viewed in the context of the seriousness of the disease, the suffering induced, the outcome in question, societal values and the natural course including the duration of the disease. In the following paragraphs we discuss a number of these issues which readers should take into account in interpreting the results. 


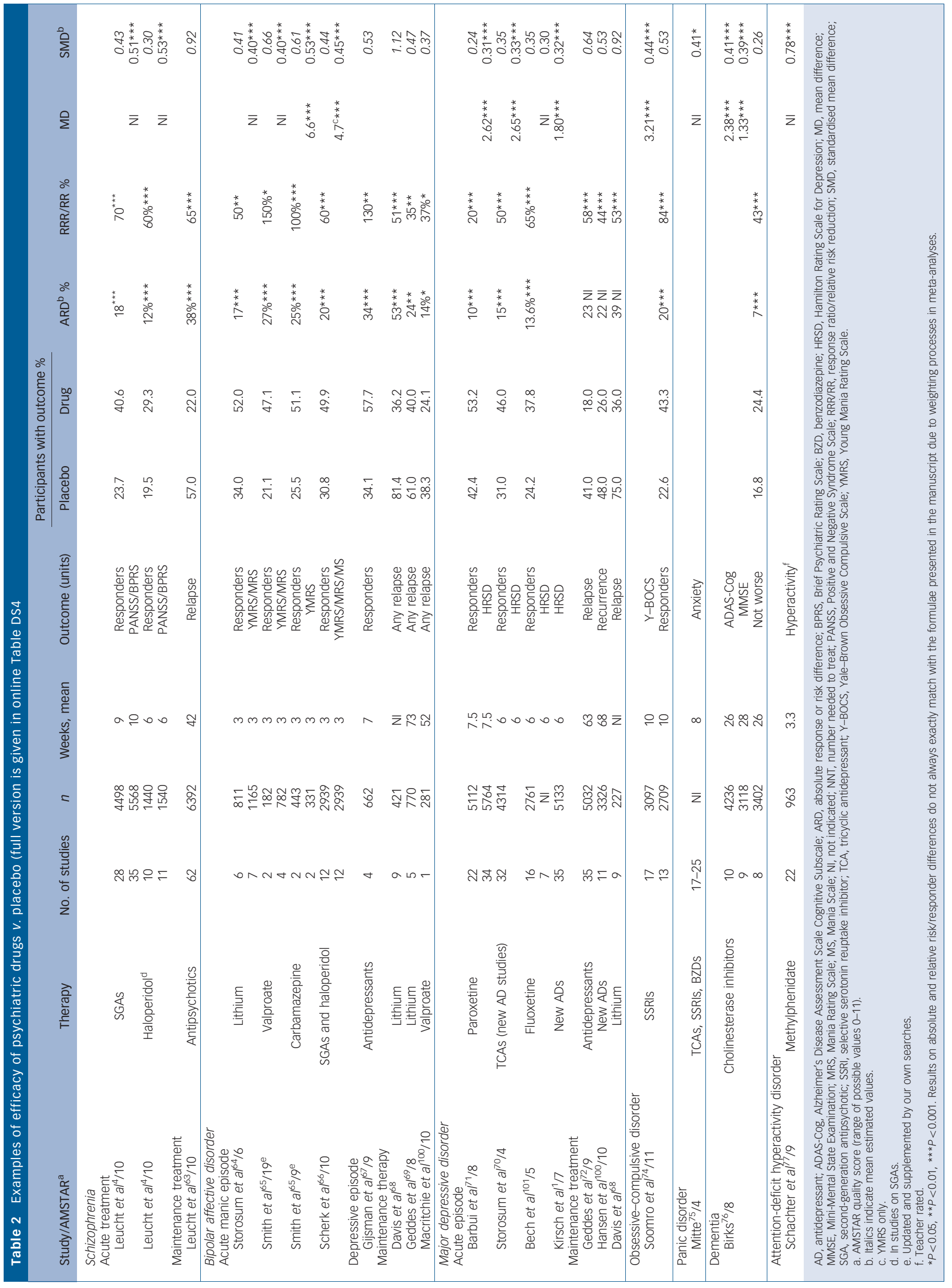




\section{Outcomes}

Psychiatry is often criticised for using rating scales which are subjective and considered 'soft' outcomes, whereas many medical treatments prevent 'hard' outcomes such as death or major events (stroke, heart attack, etc.). High blood pressure or cholesterol levels per se do not lead to suffering, therefore they should not be the primary outcome, rather their long-term consequences. Sometimes an intermediate outcome is improved but mortality increases; for example, in a large multicentre effectiveness trial for asthma $(n=26000)$, long-acting beta-2-agonists increased respiratory-related deaths. ${ }^{80}$ In diabetes, aggressive glycaemic control reduced glucose levels compared with standard care, but increased mortality rates $(n=10251){ }^{81}$

Other drugs reduce the symptoms and suffering originating directly from the disease such as oesophagitis or migraine, but their pathophysiological disease processes do not progress to death. Psychiatric drugs fall in this category. Therefore, reduction of disease severity (e.g. degree of delusions and hallucinations in schizophrenia) and prevention of future episodes are primary outcomes, and it is not entirely appropriate to criticise psychiatry for using 'soft' outcomes. This said, there is considerable room for improvement in psychiatric outcome measures, ${ }^{82}$ and death or suicide should be always reported. The example of lithium shows that some psychiatric drugs may reduce suicide rates. ${ }^{83,84}$

\section{Placebo effects}

Readers may be surprised that many effect sizes in both areas were not larger. The median of all effect sizes was 0.40 , similar to that found in another analysis of Cochrane reviews $(0.32) .{ }^{85}$ In this context there is a general misconception that with placebo all patients will have a poor outcome, but many patients will recover spontaneously owing to the natural course of the disorder (for example, a manic episode will remit by itself) and placebo effects.

\section{Effect sizes for dichotomous and continuous outcomes}

For dichotomous outcomes both relative and absolute risk reductions should be considered. There is substantial evidence showing that clinicians tend to overestimate treatment effects presented as relative risk reductions. ${ }^{86}$ For example, statins reduced cardiovascular events from approximately $18 \%$ to approximately $14 \% .^{23}$ The relative risk reduction of $22 \%$ $((1-(0.14 / 0.18)) \times 100)$ is more impressive than the absolute risk difference of $4 \%(14 \%-18 \%=|-4 \%|)$. On the other hand, if the risk in the placebo group is low, the maximally possible absolute risk reduction must be lower than the base rate (here 18\%), making the relative risk reduction more important.

In continuous outcomes the standardised mean difference (Cohen's $d$, Hedges' $g$, etc.) is necessary when different instruments are used to measure the same concept (e.g. two depression scales) or if the original unit is difficult to interpret intuitively (e.g. the score of an unknown rating scale). As the SMD is relative to the pooled standard deviation, large variability will reduce it. In psychiatry this often occurs with rating scales in somewhat ill-defined, 'variable' diseases such as depression, whereas in general medicine the measure may be a highly accurate laboratory test (e.g. serum cholesterol concentration) in a well-defined disease entity. Cohen's rule that an SMD of 0.2 is a small effect size, 0.5 medium and 0.8 a large effect size is often used, but Cohen hastened to say that the interpretation depends on the context; ${ }^{87}$ a small SMD for a fatal disease is more important than a large SMD for a transitory rash. In the future, quality-adjusted life years (QALYs) could be a uniform measure for comparisons across treatments, but these are not yet available for all drugs and we did not find this outcome in the meta-analyses. In addition, there is much debate about the validity of QALYs (see, for example, studies by Schlander ${ }^{88}$ and Griebsch et al ${ }^{89}$ ).

\section{Sample size}

Meta-analyses in somatic medicine sometimes include impressively large patient numbers, e.g. 95000 participants in studies of the primary prevention of cardiovascular events with aspirin. ${ }^{21}$ Aspirin reduced the risk of a cardiovascular event from $0.57 \%$ per year to $0.51 \%$ per year. Angiotensin-converting enzyme inhibitors for hypertension reduced 5-year mortality from $10.4 \%$ to $9.2 \%$ in 18229 participants. ${ }^{16}$ In such situations, large sample sizes are needed for two reasons: first, the aspirin $v$. placebo difference was $0.07 \%$ event and the ACE inhibitors $v$. placebo difference was $1.2 \%$ events, requiring large sample sizes for statistical significance; second, the base rate (equivalent to the risk in the placebo group) was very low (e.g. $0.57 \%$ per year without aspirin), limiting the drug effect to a maximum $0.57 \%$ per year. Nevertheless, for mortality even a small difference can be clinically meaningful. In psychiatry the difference in percentages of those responding to drug or placebo is usually higher and it has been shown that here meta-analyses with at least 1000 participants are robust. ${ }^{90}$

\section{Drug effects could accumulate over time}

The mean duration of the studies included in a meta-analysis should always be considered. For example, treated or not, few patients with hypertension will die in the course of a year. Thus, to obtain a large difference in mortality, studies of many years' duration would be necessary, but such studies are almost impossible to conduct for many reasons. Therefore, shorter studies are performed which show only small differences. Although only very long-term studies could prove this, it is likely that the reduction of mortality accumulates over time. In this context, many psychiatric drugs not only improve the acute episode but also prevent further episodes. Patients with severe recurrent depression might have 20 episodes in their lifetime, which could be reduced by medication to $10 .^{72}$

\section{Has drug efficacy decreased over the decades?}

To be systematic we generally chose the most up-to-date systematic reviews, but there is an impression that earlier meta-analyses in psychiatry yielded higher effect sizes (see online Table DS1 for some examples). In the first 103 double-blind studies in depression, summarised in 1993, approximately two-thirds responded to tricyclic antidepressants or monoamine esterase inhibitors compared with a third responding to placebo. ${ }^{91}$ The large National Institute of Mental Health schizophrenia trial, published in 1964, reported that $69 \%$ responded to antipsychotics and $24 \%$ to placebo (NNT 2, effect size 1.31 ). ${ }^{92}$ In the first large obsessive-compulsive disorder trial, published in 1991, half the sample responded to clomipramine and only $5 \%$ to placebo. $^{93}$ Recent meta-analyses found much smaller effect sizes for both the new SSRIs and clomipramine. ${ }^{94}$ The reasons for decreasing effect sizes are not entirely understood. The early trials were often small and single-centre, and methodology less well developed (blinding, scales, external auditing, statistical methods). There may also have been more publication bias, as efforts to control it have expanded only in the past two decades. Modern trials are often large, multicentre studies but have other problems such as the impossibility of recruiting severely ill patients with truly acute disorders because of ethical concerns, the availability of effective medication leaving few drug-naive patients, and the phenomenon of symptomatic volunteers answering an 
advertisement for free medication and thereby increasing placebo response. ${ }^{95}$ It is possible that there are similar temporal trends in general medicine and the phenomenon needs thorough examination.

\section{Limitations}

We made a considerable effort to be systematic, but for the reasons stated below we could not meet all criteria of a systematic review. We did not examine a single drug but put different medications in perspective, for which an established methodology does not exist.

First, we could not present a complete collection, but we chose common diseases by consensus based on frequency, importance and available treatment. It would be difficult to operationalise the selection. For example, there are diseases that are frequent but not severe (an extreme example is the common cold). Others are extremely severe but rare (e.g. certain cancers). The selection was made a priori, and once chosen all diseases and drugs were presented. We feel that the selection is representative and that the major diseases of the industrialised world are included; nevertheless, the selection process may have introduced bias.

Second, in the selection among reviews, we emphasised up-todateness and full presentation, but we compared the results of different meta-analyses on the same topic which were usually consistent. Third, a review of reviews is observational by nature: our unit of analysis was published meta-analyses, which does not exist for all drugs/indications, and the included reports differed in the exact methods, publication dates, inclusion criteria, etc. Fourth, many meta-analyses did not present the data in a consistent manner, resulting in a major challenge for us. We made substantial efforts to present the results in a consistent way by back-calculating indices, but stringent following of the PRISMA statement would facilitate future attempts. ${ }^{13}$

Fifth, we did not address side-effects. These are a serious problem of many psychotropic drugs, although improvements have been made. For example, SSRIs have much less serious toxicity than tricyclic antidepressants. General medicine drugs also have important side-effects, for example death induced by bleeding from thrombolysis or aspirin or cancer chemotherapies. It would have been simply impossible to describe side-effects as well and to balance them with efficacy, because there are many subjective judgement calls. Finally, publication bias is a major problem for meta-analyses. For example, Turner et al (see Table DS4) showed that the inclusion of unpublished antidepressant trials reduced the effect size. ${ }^{96}$ Publication bias exists in general medicine as well (see, for example, Rising et al), ${ }^{97}$ and we are not aware of evidence comparing its degree in different fields.

There are many reasons why doctors, patients and caregivers are and should be critical about psychotropic drug treatment, such as unclear disease aetiology, lack of diagnostic tests, commercial conflict of interest, unclear mechanism of drug action and sideeffects. Moreover, some people think that psychiatric disorders are purely psychological conditions that should be treated exclusively with psychotherapy. However, the efficacy of psychotropic drugs is supported by randomised controlled trials. In this context we have put psychiatric drugs in the perspective of general medicine medication.

\footnotetext{
Stefan Leucht, MD, Sandra Hierl, MD, Werner Kissling, MD, Markus Dold, MD, Department of Psychiatry and Psychotherapy, Munich Technical University, Klinikum rechts der Isar, Munich, Germany; John M. Davis, Department of Psychiatry, University of Illinois, Chicago, Illinois, USA

Correspondence: Professor Stefan Leucht, Department of Psychiatry and Psychotherapy, Technische Universität München, Klinikum rechts der Isar, Ismaningerstr. 22, 81675 München, Germany. Email: Stefan.Leucht@|rz.tum.de

First received 16 May 2011, final revision 22 Aug 2011, accepted 15 Sep 2011
}

\section{Acknowledgements}

We thank Drs Malcom Law, Toshi Furukawa, Corrado Barbui and Shelley Salpeter for replying to our requests about their studies.

\section{References}

1 Kirsch I, Deacon BJ, Huedo-Medina TB, Scoboria A, Moore TJ, Johnson BT. Initial severity and antidepressant benefits: a meta-analysis of data submitted to the Food and Drug Administration. PLOS Med 2008; 5: e45.

2 Kaduszkiewicz $\mathrm{H}$, Zimmermann T, Beck-Bornholdt HP, van den Bussche $\mathrm{H}$. Cholinesterase inhibitors for patients with Alzheimer's disease: systematic review of randomised clinical trials. BMJ 2005; 331: 321-7.

3 Moncrieff J. Lithium revisited. A re-examination of the placebo-controlled trials of lithium prophylaxis in manic-depressive disorder. Br J Psychiatry 1995; 167: 569-73.

4 Leucht S, Arbter D, Engel RR, Kissling W, Davis JM. How effective are secondgeneration antipsychotic drugs? A meta-analysis of placebo-controlled trials. Mol Psychiatry 2009; 14: 429-47.

5 Menand L. Head case: can psychiatry be a science? The New Yorker 2010; 1 March: 68-74.

6 Breggin P. Medication Madness: The Role of Psychiatric Drugs in Cases of Violence, Suicide, and Crime. St Martin's Press, 2008.

7 Kirsch I. The Emperor's New Drugs: Exploring the Antidepressant Myth. Basic Books, 2010.

8 Herold G. Innere Medizin. Gerd Herold, 2009

9 Möller HJ, Laux G, Deister A. Duale Reihe Psychiatrie und Psychotherapie, 4. Auflage. Thieme, 2009.

10 Shea BJ, Hamel C, Wells GA, Bouter LM, Kristjansson E, Grimshaw J, et al. AMSTAR is a reliable and valid measurement tool to assess the methodological quality of systematic reviews. J Clin Epidemiol 2009; 62: 1013-20.

11 The Nordic Cochrane Centre. Review Manager (RevMan) [Computer program] Version 5.0. Cochrane Collaboration, 2008.

12 Borenstein M, Hedges LV, Higgins JPT, Rothstein H. Comprehensive Meta-analysis Version 2. Biostat, 2006 (http://www.meta-analysis.com/ downloads/Meta-Analysis-Manual.pdf).

13 Liberati A, Altman DG, Tetzlaff J, Mulrow C, Gotzsche PC, Ioannidis JP, et al. The PRISMA statement for reporting systematic reviews and meta-analyses of studies that evaluate health care interventions: explanation and elaboration. PLoS Med 2009; 6: e1000100.

14 Chinn S. A simple method for converting an odds ratio to effect size for use in meta-analysis. Stat Med 2000; 19: 3127-31.

15 Law M, Morris JK, Jordan R, Wald N. Headaches and the treatment of blood pressure: results from a meta-analysis of 94 randomized placebo-controlled trials with 24,000 participants. Circulation 2005; 112: 2301-6.

16 Blood Pressure Lowering Treatment Trialists' Collaboration. Effects of different blood-pressure-lowering regimens on major cardiovascular events: results of prospectively-designed overviews of randomised trials. Lancet 2003; 362: 1527-35.

17 Wardlaw JM, Murray V, Berge E, Del Zoppo GJ. Thrombolysis for acute ischaemic stroke. Cochrane Database Syst Rev 2009; 4: CD000213.

18 Hacke W, Kaste M, Bluhmki E, Brozman M, Davalos A, Guidetti D, et al. Thrombolysis with alteplase 3 to 4.5 hours after acute ischemic stroke. N Engl J Med 2008; 359: 1317-29.

19 Sandercock PA, Counsell C, Gubitz GJ, Tseng MC. Antiplatelet therapy for acute ischaemic stroke. Cochrane Database Syst Rev 2008; 3: CD000029.

20 Sandercock PA, Counsell C, Kamal AK. Anticoagulants for acute ischaemic stroke. Cochrane Database Syst Rev 2008; 4: CD000024.

21. Baigent C, Blackwell L, Collins R, Emberson J, Godwin J, Peto R, et al. Aspirin in the primary and secondary prevention of vascular disease: collaborative meta-analysis of individual participant data from randomised trials. Lancet 2009; 373: 1849-60.

22 Law MR, Wald NJ, Rudnicka AR. Quantifying effect of statins on low density lipoprotein cholesterol, ischaemic heart disease, and stroke: systematic review and meta-analysis. BMJ 2003; 326: 1423.

23 Baigent C, Keech A, Kearney PM, Blackwell L, Buck G, Pollicino C, et al. Efficacy and safety of cholesterol-lowering treatment: prospective metaanalysis of data from 90,056 participants in 14 randomised trials of statins. Lancet 2005; 366: 1267-78.

24 Garg R, Yusuf S. Overview of randomized trials of angiotensin-converting enzyme inhibitors on mortality and morbidity in patients with heart failure. Collaborative Group on ACE Inhibitor Trials. JAMA 1995; 273: 1450-6. 
25 Lee VC, Rhew DC, Dylan M, Badamgarav E, Braunstein GD, Weingarten SR. Meta-analysis: angiotensin-receptor blockers in chronic heart failure and high-risk acute myocardial infarction. Ann Intern Med 2004; 141: 693-704.

26 Brophy JM, Joseph L, Rouleau JL. Beta-blockers in congestive heart failure. A Bayesian meta-analysis. Ann Intern Med 2001; 134: 550-60.

27 Faris R, Flather MD, Purcell H, Poole-Wilson PA, Coats AJ. Diuretics for hear failure. Cochrane Database Syst Rev 2006; 1: CD003838.

28 Hood WB, Dans AL, Guyatt GH, Jaeschke R, McMurray JJ. Digitalis for treatment of congestive heart failure in patients in sinus rhythm. Cochrane Database Syst Rev 2004; 2: CD002901.

29 Suarez-Almazor ME, Belseck E, Shea B, Homik J, Wells G, Tugwell P. Antimalarials for treating rheumatoid arthritis. Cochrane Database Syst Rev 2000; 4: CD000959.

30 Blumenauer B, Judd M, Wells G, Burls A, Cranney A, Hochberg M, et al. Infliximab for the treatment of rheumatoid arthritis. Cochrane Database Syst Rev 2002; 3: CD003785.

31 McCrory DC, Gray RN. Oral sumatriptan for acute migraine. Cochrane Database Syst Rev 2003; 3: CD002915.

32 Lampl C, Voelker M, Diener HC. Efficacy and safety of 1,000 mg effervescent aspirin: individual patient data meta-analysis of three trials in migraine headache and migraine accompanying symptoms. J Neurol 2007; 254: 705-12

33 Linde K, Rossnagel K. Propranolol for migraine prophylaxis. Cochrane Database Syst Rev 2004; 2: CD003225.

34 Mulleners WM, Chronicle EP. Anticonvulsants in migraine prophylaxis: a Cochrane review. Cephalalgia 2008; 28: 585-97.

35 British Thoracic Society. British Guideline on the Management of Asthma. Thorax 2008; 63 (suppl 4): 1-121.

36 Sin DD, Man J, Sharpe H, Gan WQ, Man SF. Pharmacological management to reduce exacerbations in adults with asthma: a systematic review and metaanalysis. JAMA 2004; 292: 367-76.

37 Ni CM, Greenstone IR, Danish A, Magdolinos $H$, Masse V, Zhang X, et al. Long-acting beta2-agonists versus placebo in addition to inhaled corticosteroids in children and adults with chronic asthma. Cochrane Database Syst Rev 2005; 4: CD005535.

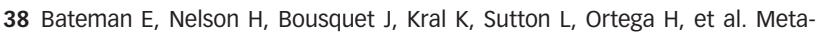
analysis: effects of adding salmeterol to inhaled corticosteroids on serious asthma-related events. Ann Intern Med 2008; 149: 33-42.

39 Salpeter SR, Buckley NS, Ormiston TM, Salpeter EE. Meta-analysis: effect of long-acting beta-agonists on severe asthma exacerbations and asthmarelated deaths. Ann Intern Med 2006; 144: 904-12.

40 Vogelmeier C, Buhl R, Criée CP, Gillissen A, Kardos P, Köhler D, et al. Guidelines for the diagnosis and therapy of COPD issued by Deutsche Atemwegsliga and Deutsche Gesellschaft für Pneumologie und Beatmungsmedizin. Pneumologie 2007; 61: e1-40.

41 Barr RG, Bourbeau J, Camargo CA, Ram FS. Tiotropium for stable chronic obstructive pulmonary disease: a meta-analysis. Thorax 2006; 61: 854-62.

42 Yang IA, Fong KM, Sim EH, Black PN, Lasserson TJ. Inhaled corticosteroids for stable chronic obstructive pulmonary disease. Cochrane Database Syst Rev 2007; 2: CD002991.

43 Salpeter SR, Buckley NS, Salpeter EE. Meta-analysis: anticholinergics, but not beta-agonists, reduce severe exacerbations and respiratory mortality in COPD. J Gen Intern Med 2006; 21: 1011-9.

44 Saenz A, Fernandez-Esteban I, Mataix A, Ausejo M, Roque M, Moher D. Metformin monotherapy for type 2 diabetes mellitus. Cochrane Database Syst Rev 2005; 3: CD002966.

45 Van de Laar FA, Lucassen PL, Akkermans RP, Van de Lisdonk EH, Rutten GE, van Weel C. Alpha-glucosidase inhibitors for type 2 diabetes mellitus. Cochrane Database Syst Rev 2005; 2: CD003639.

46 Myers RP, Regimbeau C, Thevenot T, Leroy V, Mathurin P, opolon P, et al. Interferon for interferon naive patients with chronic hepatitis $\mathrm{C}$. Cochrane Database Syst Rev 2002; 2: CD000370.

47 Brok J, Gluud LL, Gluud C. Ribavirin plus interferon versus interferon for chronic hepatitis C. Cochrane Database Syst Rev 2005; 4: CD005527.

48 Moayyedi P, Santana J, Khan M, Preston C, Donnellan C. Medical treatments in the short term management of reflux oesophagitis. Cochrane Database Syst Rev 2007; 2: CD003244.

49 Donnellan C, Sharma N, Preston C, Moayyedi P. Medical treatments for the maintenance therapy of reflux oesophagitis and endoscopic negative reflux disease. Cochrane Database Syst Rev 2005; 2: CD003245

50 Sutherland L, Macdonald JK. Oral 5-aminosalicylic acid for induction of remission in ulcerative colitis. Cochrane Database Syst Rev 2006; 2: CD000543.
51 Sutherland L, Macdonald JK. Oral 5-aminosalicylic acid for maintenance of remission in ulcerative colitis. Cochrane Database Syst Rev 2006; 2: CD000544.

52 Filippini G, Brusaferri F, Sibley WA, Citterio A, Ciucci G, Midgard R, et al. Corticosteroids or ACTH for acute exacerbations in multiple sclerosis. Cochrane Database Syst Rev 2000; 4: CD001331.

53 Rice GP, Incorvaia B, Munari L, Ebers G, Polman C, D'Amico R, et al. Interferon in relapsing-remitting multiple sclerosis. Cochrane Database Syst Rev 2001; 4: CD002002.

54 National Collaborating Centre for Chronic Conditions. Parkinson's Disease. National Clinical Guideline for Diagnosis and Management in Primary and Secondary Care. Royal College of Physicians, 2006.

55 Fahn S, Oakes D, Shoulson I, Kieburtz K, Rudolph A, Lang A, et al. Levodopa and the progression of Parkinson's disease. N Engl J Med 2004; 351: 2498508.

56 Early Breast Cancer Trialists' Collaborative Group. Effects of chemotherapy and hormonal therapy for early breast cancer on recurrence and 15-year survival: an overview of the randomised trials. Lancet 2005; 365: 1687-717.

57 Bria E, Gralla RJ, Raftopoulos H, Cuppone F, Milella M, Sperduti I, et al. Magnitude of benefit of adjuvant chemotherapy for non-small cell lung cancer: meta-analysis of randomized clinical trials. Lung Cancer 2009; 63: 50-7.

58 Lung Cancer Collaborative Group. Chemotherapy in non-small cell lung cancer: a meta-analysis using updated data on individual patients from 52 randomised clinical trials. BMJ 1995; 311: 257-63.

59 Young J, De Sutter A, Merenstein D, van Essen GA, Kaiser L, Varonen $H$, et al. Antibiotics for adults with clinically diagnosed acute rhinosinusitis: a metaanalysis of individual patient data. Lancet 2008; 371: 908-14.

60 Glasziou PP, Del Mar CB, Sanders SL, Hayem M. Antibiotics for acute otitis media in children. Cochrane Database Syst Rev 2004; 1: CD000219.

61 Falagas ME, Kotsantis IK, Vouloumanou EK, Rafailidis PI. Antibiotics versus placebo in the treatment of women with uncomplicated cystitis: a metaanalysis of randomized controlled trials. J Infect 2009; 58: 91-102.

62 Nelson RL, Glenny AM, Song F. Antimicrobial prophylaxis for colorectal surgery. Cochrane Database Syst Rev 2009; 1: CD001181.

63 Leucht M, Komossa K, Heres S, Kissling W, Davis JM. An update on relapse prevention with antipsychotic drugs compared to placebo (abstract). Schizophr Res, in press.

64 Storosum JG, Wohlfarth T, Schene A, Elferink A, van Zwieten BJ, van den Brink W. Magnitude of effect of lithium in short-term efficacy studies of moderate to severe manic episode. Bipolar Disord 2007; 9: 793-8.

65 Smith LA, Cornelius V, Warnock A, Tacchi MJ, Taylor D. Pharmacological interventions for acute bipolar mania: a systematic review of randomized placebo-controlled trials. Bipolar Disord 2007; 9: 551-60.

66 Scherk H, Pajonk FG, Leucht S. Second-generation antipsychotic agents in the treatment of acute mania: a systematic review and meta-analysis of randomized controlled trials. Arch Gen Psychiatry 2007; 64: 442-55.

67 Gijsman HJ, Geddes JR, Rendell JM, Nolen WA, Goodwin GM. Antidepressants for bipolar depression: a systematic review of randomized, controlled trials. Am J Psychiatry 2004; 161: 1537-47.

68 Davis JM, Janicak PG, Hogan DM. Mood stabilizers in the prevention of recurrent affective disorders: a meta-analysis. Acta Psychiatr Scand 1999; 100: 406-17.

69 Geddes JR, Burgess S, Hawton K, Jamison K, Goodwin GM. Long-term lithium therapy for bipolar disorder: systematic review and meta-analysis of randomized controlled trials. Am J Psychiatry 2004; 161: 217-22.

70 Storosum JG, Elferink AJ, van Zwieten BJ, van den Brink W, Gersons BP, van Strik R, et al. Short-term efficacy of tricyclic antidepressants revisited: a meta-analytic study. Eur Neuropsychopharmacol 2001; 11: 173-80.

71 Barbui C, Furukawa TA, Cipriani A. Effectiveness of paroxetine in the treatment of acute major depression in adults: a systematic re-examination of published and unpublished data from randomized trials. CMAJ 2008; 178: 296-305.

72 Geddes JR, Carney SM, Davies C, Furukawa TA, Kupfer DJ, Frank E, et al. Relapse prevention with antidepressant drug treatment in depressive disorders: a systematic review. Lancet 2003; 361: 653-61.

73 Hansen RA, Gartlehner G, Lohr KN, Gaynes BN, Carey TS. Efficacy and safety of second-generation antidepressants in the treatment of major depressive disorder. Ann Intern Med 2005; 143: 415-26.

74 Soomro GM, Altman D, Rajagopal S, Oakley-Browne M. Selective serotonin re-uptake inhibitors (SSRIs) versus placebo for obsessive compulsive disorder (OCD). Cochrane Database Syst Rev 2008; 1: CD001765.

75 Mitte K. A meta-analysis of the efficacy of psycho- and pharmacotherapy in panic disorder with and without agoraphobia. J Affect Disord 2005; 88: $27-45$. 
76 Birks J. Cholinesterase inhibitors for Alzheimer's disease. Cochrane Database Syst Rev 2006; 1: CD005593.

77 Schachter HM, Pham B, King J, Langford S, Moher D. How efficacious and safe is short-acting methylphenidate for the treatment of attention-deficit disorder in children and adolescents? A meta-analysis. CMAJ 2001; 165: 1475-88.

78 Faraone SV, Biederman J. Efficacy of Adderall for attention-deficit/ hyperactivity disorder: a meta-analysis. J Atten Disord 2002; 6: 69-75.

79 Cheng JY, Chen RY, Ko JS, Ng EM. Efficacy and safety of atomoxetine for attention-deficit/hyperactivity disorder in children and adolescents - metaanalysis and meta-regression analysis. Psychopharmacology (Berl) 2007; 194 197-209.

80 Nelson HS, Weiss ST, Bleecker ER, Yancey SW, Dorinsky PM. The Salmetero Multicenter Asthma Research Trial: a comparison of usual pharmacotherapy for asthma or usual pharmacotherapy plus salmeterol. Chest 2006; 129: $15-26$.

81 The Action to Control Cardiovascular Risk in Diabetes Study Group. Effects of intensive glucose lowering in Type 2 diabetes. N Engl J Med 2008; 358 : 2545-59.

82 Leucht S, Davis JM, Engel RR, Kane JM, Wagenpfeil S. Defining 'response' in antipsychotic drug trials: recommendations for the use of scale-derived cutoffs. Neuropsychopharmacology 2007; 32: 1903-10.

83 Baldessarini RJ, Tondo L, Hennen J. Lithium treatment and suicide risk in major affective disorders: update and new findings. J Clin Psychiatry 2003; 64 (suppl 5): 44-52.

84 Cipriani A, Pretty $\mathrm{H}$, Hawton $\mathrm{K}$, Geddes JR. Lithium in the prevention of suicidal behavior and all-cause mortality in patients with mood disorders: a systematic review of randomized trials. Am J Psychiatry 2005; 162: 1805-19.

85 Furukawa TA, Watanabe N, Omori IM, Montori VM, Guyatt GH. Association between unreported outcomes and effect size estimates in Cochrane meta-analyses. JAMA 2007; 297: 468-70.

86 Covey J. A meta-analysis of the effects of presenting treatment benefits in different formats. Med Decis Making 2007; 27: 638-54.

87 Cohen J. Statistical Power Analysis for the Behavioral Sciences (second edition). Erlbaum, 1988.

88 Schlander M. Measures of efficiency in healthcare: QALMs about QALYS. Z Evid Fortbild Qual Gesundhwes 2010; 104: 214-26.

89 Griebsch I, Coast J, Brown J. Quality-adjusted life-years lack quality in pediatric care: a critical review of published cost-utility studies in child health. Pediatrics 2005; 115: e600-14.
90 Trikalinos TA, Churchill R, Ferri M, Leucht S, Tuunainen A, Wahlbeck K, et al. Effect sizes in cumulative meta-analyses of mental health randomized trials evolved over time. J Clin Epidemiol 2004; 57: 1124-30.

91 Davis JM, Wang Z, Janicak PG. A quantitative analysis of clinical drug trials for the treatment of affective disorders. Psychopharmacol Bull 1993; 29: 175-81.

92 Cole JO. Phenothiazine treatment in acute schizophrenia. Arch Gen Psychiatry 1964; 10: 246-61.

93 Clomipramine Collaborative Study Group. Clomipramine in the treatment of patients with obsessive-compulsive disorder. Arch Gen Psychiatry 1991; 48: 730-8.

94 Ackerman DL, Greenland S. Multivariate meta-analysis of controlled drug studies for obsessive-compulsive disorder. J Clin Psychopharmacol 2002; 22: $309-17$.

95 Walsh BT, Seidman SN, Sysko R, Gould M. Placebo response in studies of major depression: variable, substantial, and growing. JAMA 2002; 287: 1840-7.

96 Turner EH, Matthews AM, Linardatos E, Tell RA, Rosenthal R. Selective publication of antidepressant trials and its influence on apparent efficacy. N Engl J Med 2008; 358: 252-60.

97 Rising K, Bacchetti P, Bero L. Reporting bias in drug trials submitted to the Food and Drug Administration: review of publication and presentation. PLOS Med 2008; 5: e217.

98 Flather MD, Yusuf S, Kober L, Pfeffer M, Hall A, Murray G, et al. Long-term ACE-inhibitor therapy in patients with heart failure or left-ventricular dysfunction: a systematic overview of data from individual patients. ACEInhibitor Myocardial Infarction Collaborative Group. Lancet 2000; 355 : 1575-81.

99 Suarez-Almazor ME, Belseck E, Shea B, Wells G, Tugwell P. Methotrexate for rheumatoid arthritis. Cochrane Database Syst Rev 2000; 2: CD000957.

100 Macritchie KA, Geddes JR, Scott J, Haslam DR, Goodwin GM. Valproic acid, valproate and divalproex in the maintenance treatment of bipolar disorder. Cochrane Database Syst Rev 2001; 3: CD003196.

101 Bech $\mathrm{P}$, Cialdella P, Haugh MC, Hours A, Boissel JP, Birkett MA, et al Meta-analysis of randomised controlled trials of fluoxetine $v$. placebo and tricyclic antidepressants in the short-term treatment of major depression. Br J Psychiatry 2000; 176: 421-8.

102 Hansen R, Gaynes B, Thieda P, Gartlehner G, Veaugh-Geiss A, Krebs E, et al. Meta-analysis of major depressive disorder relapse and recurrence with second-generation antidepressants. Psychiatr Serv 2008; 59: 1121-30. 